\title{
Surface Rupture of the Changureh Earthquake in northwest Iran on June 22, 2002
}

\section{Takao Miyata*, Ahmad Khorsandi ${ }^{* *}$ and Jun-ichiro Yurugi ***}

\author{
Received August 23, 2002. Accepted November 21, 2002 \\ * Department of Earth and Planetary Sciences, Faculty of Science, Kobe University. Nada-ku, Kobe, 657-8501, Japan \\ ** Power and Water Institute of Technology (PWIT), Tehran, I.R. Iran \\ *** Department of Global Development Science, Graduate School of Science and Technology, Kobe University. Nada-ku, Kobe, 657-8501, Japan
}

The M 6. 3 Changureh Earthquake occurred on June 22, 2002 at $7: 28$ (local time) in the Abegarm region, $225 \mathrm{~km}$ west of Tehran City, Iran. Epicenter is N $35^{\circ} 40^{\prime} 12^{\prime \prime}$ and E $48^{\circ} 55^{\prime} 48^{\prime \prime}$. Although the earthquake magnitude is relatively small, it caused a severe damage for the adobe-style buildings occupied in Abdarreh-Changureh area. The geology of this area is composed mainly of the Miocene strata (claystone, siltstone, red sandstone, conglomerate and marl). Their strata are partly covered with the Quaternary thinly-bedded gravel. In the area between Changureh village and the east of Abdarreh village, surface ruptures appeared distinctly

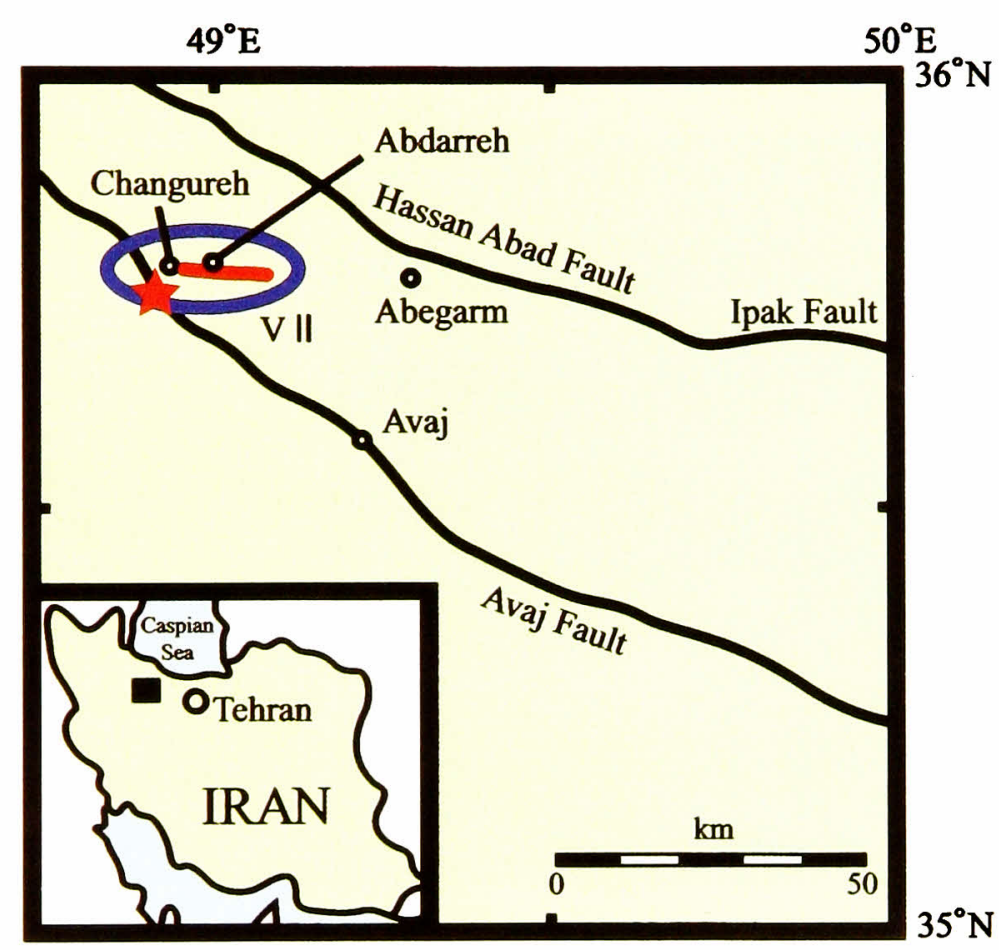

(Fig. 1). Therefore we will report promptly them.

Acknowledgements We thank Drs. N. Hassani of PWIT and S. Eshghi of IIEES for their valuable suggestions, and T. Azuma of GSJ/AIST for his useful comments and careful reviewing.

\section{References}

Bolourchi M.H., 1979, Explanatory text of the Kaboudar Ahang Quadrangle Map1 :250,000. Geol. Surv. Iran, Rept D 5, 107 p.

Fig.1. Seismotectonic map in the Abegarm-Avaj region, northwest Iran (modified from Bolourchi, 1979). An asterisk means an epicenter of the Changureh Earthquake. Strike of surface rupture is generally WNW-ESE. The length of the surface rupture is about $15 \mathrm{~km}$. Red line; Surface rupture, Blue ellipse; Severe damage area of the seismic intensity VII in EMS-98 scale.
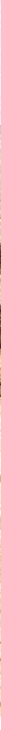

Fig. 2. Severe damages of the adobe-style building in Abdarreh village (N $35^{\circ} 48^{\prime} 52^{\prime \prime}$, E $48^{\circ} 59^{\prime} 43^{\prime \prime}$ ). The severe damage produced along a westward extension of the surface rupture shown in next Fig. 3. A in Fig. 2 is the same building as in Fig. 3 . Red broken line; Surface rupture, Photographs of Figs. 2-6 taken 23 July, 2002. 


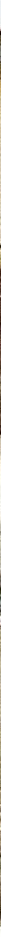

Fig. 3. A surface rupture (F) appeared at Abdarreh village. The building (right of figure) above the surface rupture was destroyed.

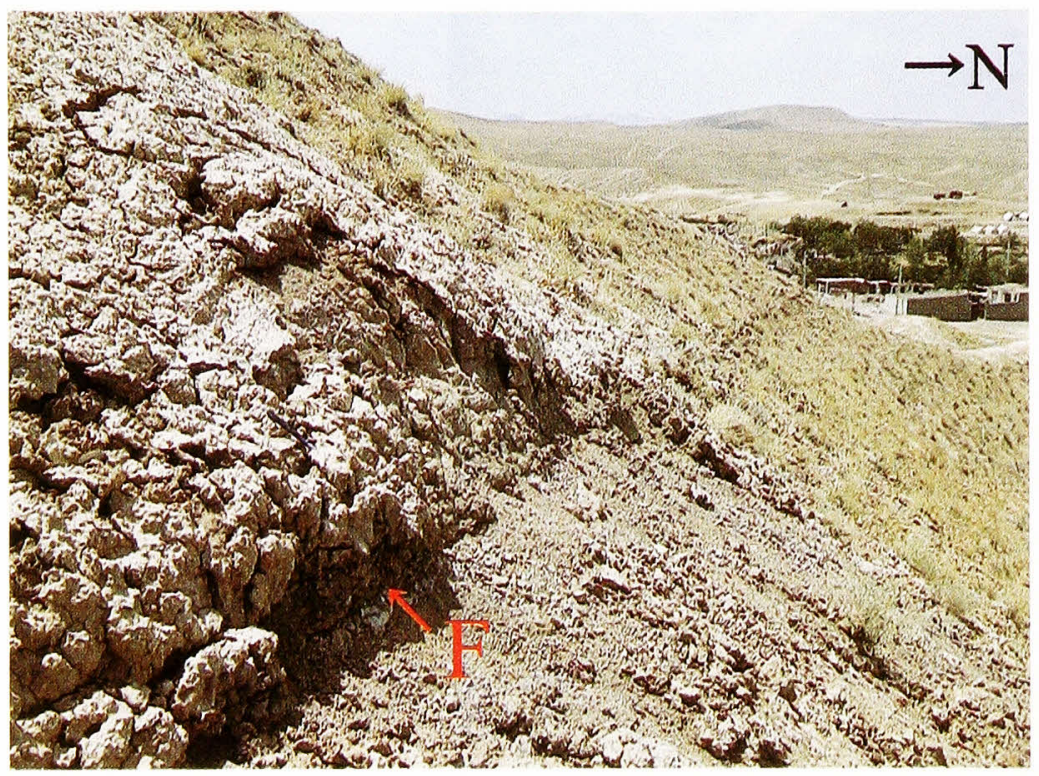

Fig. 4. The surface rupture (F) appeared on a hill on the Miocene strata at Abdarreh village during the earthquake. Along the rupture, the western side thrust up to the eastern side. The thrust plane has a strike of $\mathrm{N} 56-66^{\circ} \mathrm{W}$ and a dip of $32^{\circ} \mathrm{SW}$. A vertical displacement is a range of 5 $-10 \mathrm{~cm}$. Pencil for scale.

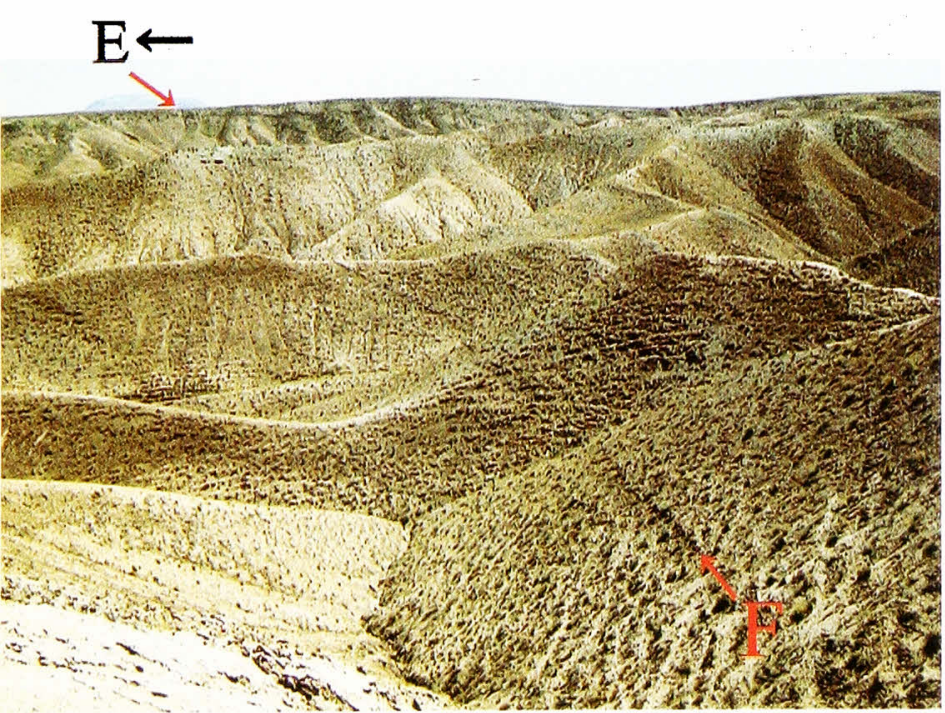

Fig. 5. The surface rupture $(F)$ is easily traceable from $B$ of Fig. 3 to the east (left). It cuts spurs and valleys.
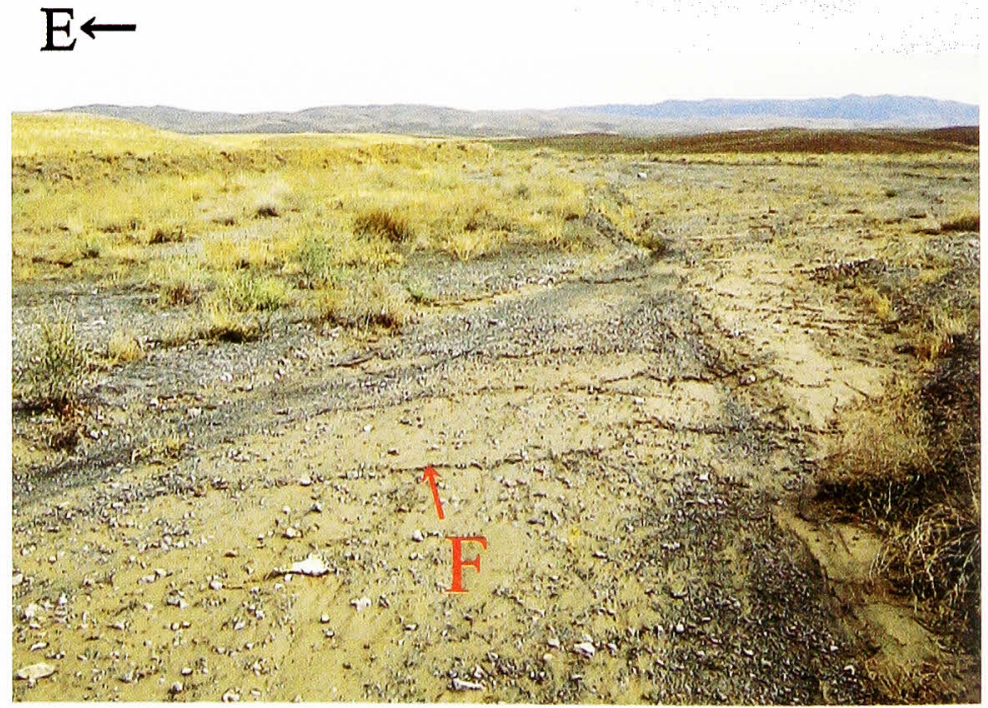

Fig. 6. A dried-up river, striking $\mathrm{N} 34^{\circ} \mathrm{E}$, was ruptured in 2002. It is located at $10-\mathrm{km}$ east of Changureh village (N $35^{\circ}$ $46^{\prime} 54^{\prime \prime}$, E $\left.48^{\circ} 59^{\prime} 43^{\prime \prime}\right)$. The strike of the four fractures (F) is $\mathrm{N} 88^{\circ} \mathrm{E}$ (or W). Spacing of the fracture is 1 to $5 \mathrm{~m}$. 